\title{
Arbitrary Fairness in Rewards and Punishments
}

\author{
Ellen R. K. Evers ${ }^{1}$, Michael O’Donnell' ${ }^{2}$, Yoel Inbar ${ }^{3}$ \\ ${ }^{1}$ University of California, Berkeley \\ ${ }^{2}$ Georgetown University \\ ${ }^{3}$ University of Toronto
}

Working paper, last updated on 09-11-2019

Author note: We thank Ariana Munroe and Cjache Kang for their help running Study 4. This research was supported in part by the Berkeley X-Lab and the Fetzer Franklin fund of the John E. Fetzer Memorial Trust. 


\begin{abstract}
People have a strong preference for fairness. For many, fairness means equal rewards and punishments for equal efforts and offences. However, this belief does not specify the units in which equality should be expressed. We show that people generally fail to take the interchangeability of units into account when judging and assigning fair punishments and rewards. As a consequence, judgments about and distributions of resources are strongly influenced by arbitrary decisions about which unit to express them in. For example, if points represent different monetary values for different recipients, people attempt to distribute money equally if money is salient, but attempt to distribute points equally if points are salient. Because beliefs about fairness are a fundamental principle in many domains, the implications of these findings are broad. Essentially any distribution of outcomes can be made to appear more or less fair by changing the units these outcomes are expressed in.
\end{abstract}

Keywords: Fairness, Punishments and Rewards, Heuristics, Simple beliefs, Equity 
People care about fairness. In their interpersonal relationships, people strive to fairly balance costs and benefits (Fiske, 1991). When interacting with strangers in economic games, people are reluctant to maximize their earnings at the expense of fairness (Bolton, Katok, \& Swift, 1998; Fehr \& Schmidt, 1999; Rabin, 1993). In many cases, people feel that equal outcomes exemplify the concept of fairness (e.g., Fehr \& Schmidt, 1999), so much so that they reject outcome-maximizing but unequal ultimatum game offers, even if these offers are worth several days' wages (Heinrich, et al., 2005). Because fairness involves moral beliefs, preferences over distributions are different from typical mundane preferences. For example, while Yoel prefers bananas to strawberries, observing Mike choosing strawberries over bananas doesn't bother Yoel. Fairness, however, is different. When people merely observe an interaction that they themselves perceive to be unfair, people are often willing to give up substantive amounts of money just to punish the person perceived to be acting unfairly (e.g., Marlowe, et al., 2008). Similar behavior can be found in primates (Brosnan and de Waal, 2003), suggesting that fairness-preferences are much more fundamentally held than other preferences.

Although it is descriptively true that people often prefer equal outcomes, this statement elides an important question: equal outcomes in which unit? A \$200 fine for everyone who exceeds the speed limit by 20 miles per hour seems fair if the unit is dollars. However, this means that a higher-income speeder needs to work fewer hours to pay the fine than does a lowerincome speeder. Similarly, 20 hours of community service for everyone seems fair if the unit is hours. But higher-wage offenders face a significantly greater opportunity cost of lost wages than lower-wage offenders. In other words, outcomes that are equal when expressed in one unit can be unequal in another. If people use equality to judge fairness (Messick, 1993), then could the same fines appear more or less fair depending on how they are expressed? 
Even though people strongly value fairness, and as such could be expected to have welldeveloped fairness preferences, there are reasons to think that people may be inconsistent in their preferences across different units. First, people are bad at unit conversions. When comparing the fuel efficiency of cars, for example, people should translate miles-per-gallon to gallons-permiles, but many do not do so spontaneously (Larrick \& Soll, 2008). Similarly, when evaluating products that offer time savings (e.g., food processors), people fail to translate rotations-persecond to the more informative seconds-per-rotation (De Langhe \& Puntoni, 2016). In these cases, people make their judgments based on the salient units rather than their underlying meaning (Kahneman \& Frederick, 2002). However, when participants are offered information that elucidate the relationship between the two units, their judgments converge with the outcome optimizing level (e.g., when miles per gallon is translated into gallons per mile, participants become much better at choosing the most fuel-efficient options; Larrick \& Soll, 2008).

Framing effects can lead to inconsistent judgments in domains in which the decisionmaker does not hold strong beliefs or is only peripherally involved. Moreover, when decisionmakers become more informed, or the decision becomes more important, framing-induced inconsistencies often disappear (Levin, Schneider, \& Gaeth, 1998). Given the moral importance placed on fairness (Graham, Haidt, \& Nosek, 2009; Rai \& Fiske, 2011), these beliefs should be the least likely to be affected by arbitrary influences, and one might expect that people would be strongly motivated to detect and resolve inconsistencies in their fairness judgments. However, although moral beliefs are often strongly held, they can also be affected by normativelyirrelevant framing differences. For example, the same profit-seeking behavior of companies is judged to be fair or unfair depending on the reference point the evaluator uses (Kahneman, Knetsch, \& Thaler, 1986a). Moreover, when people are pushed to explain or provide arguments 
for their moral preferences, they often fail to do so (Haidt, 2001, c.f. Royzman, Kim, \& Leeman, 2015). Finally, when people are confronted with their inconsistent moral beliefs, they acknowledge the inconsistencies, but still stick with their conflicting beliefs (Evers, Inbar, Blanken, \& Oosterwijk, 2016).

Taken together, the current understanding of fairness, moral beliefs, and framing effects leads to three contradicting predictions. Because fairness is such an important and fundamental component of everyday decisions, we might expect people to have a well-developed moral framework about what is and what is not fair, and as a consequence it should not matter in which units outcomes are expressed. Alternatively, because we know people have difficulty working with interchangeable units, we might expect that units of expression do affect fairness judgments, but that making the decision context more transparent removes these inconsistencies. This would be consistent with a "rationalist" account of moral judgment, according to which people reach moral conclusions by careful thought and reflection (Kohlberg, 1969; Piaget, 1923; Turiel, 1983). On such an account, providing people with the information necessary to make judgments consistent should produce consistency. There is, however, a contrasting "intuitionist" account, according to which moral judgments are generally based on quick and relatively automatic moral intuitions (Haidt, 2001). In the current case, this would imply that people largely judge fairness based on a relatively unreflective intuition as to whether a distribution "feels equal." If this is the case, we would expect the unit in which outcomes are expressed to affect fairness judgments, and further, we would expect that no intervention, not even full transparency, would make the effect of the unit of expression disappear completely.

We test these questions in 4 sets of studies (9 experiments). In Study 1 we elicit fairness judgments across a variety of contexts and found that participants predominantly judge fairness 
based on equality in expressed units. In Study 2, we built on Study 1 by explicitly converting the salient outcome from one unit to the other (e.g., time to money or money to time). We found that although this does affect judgments of fairness, there is a substantial remaining preference for surface equality (“arbitrary fairness"). In Study 3, we tested if the preference for arbitrary fairness extends to distributing (rather than merely evaluating) outcomes and found that it does. Finally, in Study 4 we found in an incentive compatible setting that people awarded themselves cash bonuses differently depending on which unit is salient.

We report all conditions and all variables measured. We predetermined the sample size for all studies and collected data until reaching the predetermined number. All studies were preregistered. All data and materials are available at: https://osf.io/9tcbx/?view_only=cd07bb1e116848e695d279049a7df067.

\section{Study 1a}

First, we tested the preference for arbitrary fairness in the context of punishments.

\section{Participants and design}

In Study 1a, 208 participants (99 male, 109 female, $M_{\text {age }}=34.7, S D=10.4$ ) were recruited on Amazon Mechanical Turk (MTurk) and randomly assigned to one of two conditions. In both conditions we presented participants with a scenario describing two people, Alan and Bob. Participants read that Alan and Bob are both freelancers in high demand, so they could work as many hours as they wanted. They were also informed that Alan made $\$ 50$ per hour and Bob $\$ 25$ per hour. Then participants read that both were caught running the same red light. In the money condition participants read that Alan was fined \$200 and Bob was fined \$150. In the time condition, participants read that Alan was sentenced to four hours of community service and Bob was sentenced to six. Because participants were told that both Alan and Bob could work as much 
or as little as they wanted, a $\$ 200$ fine for Alan is equivalent to four extra hours of work. This also, of course, means that instead of doing four hours of community service he could have worked and earned $\$ 200$. Similarly, for Bob, $\$ 150$ is equivalent to six hours of work, and six hours of community service thus has an opportunity cost of $\$ 150$. Participants evaluated the fairness of the fines on a 100-point scale ranging from -50 "extremely unfair to Alan" to +50 "extremely unfair to Bob" (the zero point was labelled as "fair").

\section{Results}

When the punishment was administered in money, participants believed the fine to be unfair to Alan (who had to pay $\$ 200$ as compared to Bob's $\$ 150 ; M=-15.1, S D=28.0$ ). However, when the fine was administered as community service, participants believed the fine to be unfair to Bob (who had to work six hours as compared to Alan's four; $(M=27.9, S D=22.5$; $t(206)=12.3, p<.001, d=1.70$, diff $=43.0,95 \% \mathrm{CI}_{\text {diff: }} 36.1$ to 49.9$)$. Note that although it is possible that participants believe leisure time is less valuable than work time, or that the income is income before taxes rather than income after taxes, none of those inferences can explain the above described pattern of results. Those inferences would lead to an attenuation of judgments, but not a full reversal (since changes in the weighting of units does not affect their rankordering).

\section{Study 1b}

One possible explanation for the differences in Study 1a could be that people who are unsure about what the fair punishment is assume that governments and policy makers-makers have already determined for which violations the fair punishment should be expressed in time, and for which in money. If this is what our participants believe, then the judgments described in Study 1a would not be incoherent because the units used are not perceived to be interchangeable. 
To test this possibility, we conducted a study in which we used a clearly arbitrary unit, points (see also; Hsee, Yu, Zhang, \& Zhang, 2003; Furlong \& Opfer, 2009). Additionally, this study only examined gains.

\section{Participants and Design}

Participants in Study 1b were 200 MTurk workers (97 male, 103 female, $M_{\text {age }}=35.2, S D$ $=11.6$ ) who were randomly assigned to one of two conditions. All participants read about three students who participated in a psychology experiment and who were randomly assigned to one of three roles. Two of the students were randomly assigned to the role of worker 1 (Brian) and worker 2 (Max). Worker 1 would earn $\$ 0.50$ per point, while worker 2 earned $\$ 1$ per point. The third student, Don, was a supervisor who could assign a 40-point ( $\$ 27.50$ dollar) bonus to the two students if they each completed at least 20 tasks. In the money condition participants read that Brian received $\$ 12.50$ while Max received $\$ 15$, in the points condition they read that Brian received 25 points while Max received 15 points. Note that since these points have no other meaning than representing value within this experiment, the two situations are logically equivalent. All participants then judged the fairness of the allocation on a 100-point scale anchored on -50: extremely unfair to Brian, and +50: extremely unfair to Max.

\section{Results}

Consistent with Study 1a, participants judged the bonus to be unfair to Brian in the money condition $(M=-16.96, S D=24.1)$, but unfair to Max in the points condition. $(M=7.45$, $S D=24.1, t(198)=7.52, p<.001, d=1.07$, diff $=24.4,95 \% \mathrm{CI}_{\text {diff: }}: 18.0$ to 30.8$)$. 

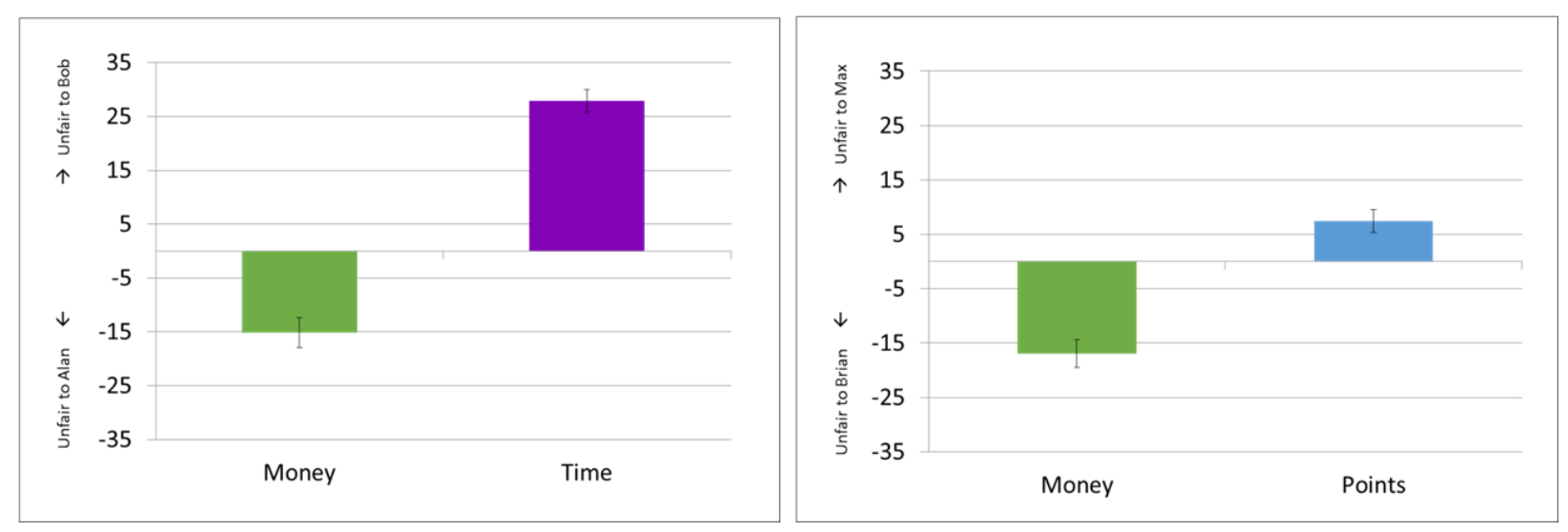

Fig. 1. Participants rated the fairness of each punishment (Study 1a, left panel) or reward (Study 1b, right panel) on a 101-point scale. Error bars represent standard errors.

\section{Discussion}

Similar to Study 1a, participants judged fairness by relying on the salient unit the outcome was expressed in. Two additional studies in the Supplemental Material (SM) tested the generalizability of the effect. Combined, these studies provide evidence that the same outcomes can be judged both fair and unfair to recipients depending on the units they are expressed in.

\section{Study 2}

People rely on salient units when judging the fairness of outcomes, but do they believe they should do this? If the results we have observed are due to a simple equating heuristic that can be counteracted by increasing the salience of the alternative units in which the allocation could be expressed, it would suggest that the preference for arbitrary fairness is in fact quite fragile. In that case, inconsistencies could easily be overcome by informing decision-makers about the bias, making the underlying structure of the decision more salient, or fostering more deliberation (i.e., greater System 2 processing, Chaiken, 1980; Shah \& Oppenheimer, 2008).

It is also possible that the preference for arbitrary fairness is strong enough that it emerges even when the conversion between units is completely transparent. This would make the 
arbitrary fairness effect more akin to phenomena such as the ratio bias, the conjunction fallacy, or mental accounting effects, where intuitions are strong enough to override people's explicit knowledge of the "correct" response (Denes-Raj \& Epstein, 1994; Kahneman \& Tversky, 2013; Kahneman \& Tversky, 1996).

\section{Study 2a}

\section{Participants and Design}

Participants were 202 workers recruited from MTurk (114 male, 87 female 1 missing; $M_{\text {age }}=34.5, S D=10.6$ ). Study $2 \mathrm{a}$ used a 2 (units - between) by 2 (time - within) mixed design. These participants were randomly assigned to one of two conditions. In both conditions, participants read the same scenario as in Study 1a. Next, all participants indicated how fair they perceived the fine to be, on the same scale as in Study 1a. After judging the fairness of the fine, participants who initially saw the fine expressed in dollars were shown a new page in which it was explained that because Alan and Bob have different incomes, this means that Alan would have to work 3 hours to pay the $\$ 150$ fine, while Bob would have to work 4 hours to pay the $\$ 100$ fine (i.e., the monetary fines were re-expressed in terms of working hours). We then reminded participants of the original fines in dollars and asked them to re-rate how fair they thought the fines were (we noted that it would be completely acceptable to repeat their initial rating). Participants in the time condition saw the initial community service punishment translated into foregone wages instead, and also evaluated the fairness of the punishment again.

\section{Results}

Replicating the results of Study 1a, participants judged the fine expressed in money to be unfair to Alan $(M=-18.6 S D=19.3)$, whereas the same fine expressed in time was perceived to be unfair to Bob $(M=14.2, S D=22.1 ; t(200)=11.22, p<.001, d=1.57$, diff $=32.7,95 \%$ 
$\mathrm{CI}_{\text {diff: }}$ 27.0 to 38.5 . We then conducted a repeated-measures ANOVA to investigate to which degree, participants updated their beliefs after the time-money exchange was explained. Using units as the between-subjects factor and time (pre- or post-translation) as the within-subjects factor, we found a non-significant effect of time (meaning that the overall average judgment did not change between period 1 and period 2), a main effect of units; $F(1,200)=103.1, p<.001$, $\eta_{\mathrm{p}}^{2}=.34$, and crucially, a significant interaction effect; $F(1,200)=13.0, p<.001, \eta_{\mathrm{p}}^{2}=.06$ Participants in the money-fine condition updated their judgments to $M=-13.9, S D=19.7$ and in the time-fine condition to $10.5 S D=24.9, \operatorname{diff}=24.3,95 \% \mathrm{CI}_{\mathrm{diff}}: 18.1$ to 30.5 . In other words, the reduction in the difference in fairness judgments pre-and post-translation is consistent with the belief that people should take equivalence across units into account, participants on average changed their judgments after they were provided with more information, attenuating the difference between the two conditions (see Figure 2, first panel). However, a large and statistically significant difference still remained between the two conditions post-translation, meaning that even though participants believed to some degree that their judgments should be unit-independent, they did not completely update their judgments. We replicated Study 2 a twice with larger samples (total $N=4665$ ) and found the same results (see SM).

\section{Study 2b}

Study $2 \mathrm{~b}$ is a conceptual replication of Study $2 \mathrm{a}$, using bonuses rather than punishments. Additionally, it employs a between-subjects design rather than a mixed design.

\section{Participants and Design}

Participants were 813 workers recruited from MTurk (394 male, 416 female, 2 nonbinary, 1 missing; $M_{\text {age }}=35.9, S D=11.6$ ) were randomly assigned to one of four conditions. 
This study employed a 2 (units: points or money) by 2 (translation provided or control) betweensubjects design. In all conditions, participants read the same scenario as in Study $1 \mathrm{~b}$. The control conditions followed the design of Study 1b; participants indicated how fair they thought the bonus was when expressed in points or money. In the translation conditions, participants saw the same bonus but before assessing its fairness, we explicitly translated the bonus into the other unit. For example, the participants who saw the 25-point bonus to Brian and 15-point bonus to Max were told that, because Brian gets $\$ 0.50$ per point and Max $\$ 1$, this results in a $\$ 12.50$ bonus for Brian, and a $\$ 15$ bonus for Max. They then rated the fairness of the bonus.

\section{Results}

The results of Study $2 \mathrm{~b}$ resemble those of Study 2a (see Figure 2, second panel). We found a main effect of expressing the bonus in points rather than money; $F(1,809)=87.0, p<$ $.001, \mathrm{\eta}_{\mathrm{p}}^{2}=.10$, no main effect of adding the translation; $F(1,809)=0.01, p=.91$, and crucially, a significant interaction effect; $F(1,809)=18.4, p<.001, \mathrm{\eta}_{\mathrm{p}}^{2}=.02$. Inspection of the means reveals that, replicating the results of Study 1b, participants judged the bonus expressed in points to be unfair to Max $(M=3.4 S D=19.3)$, whereas the same bonus expressed in money was judged as unfair to Brian $(M=-17.6, S D=21.6 ; t(408)=10.3, p<.001, d=1.02$, diff $=21.0$, 95\% $\mathrm{CI}_{\text {diff: }} 17.0$ to 25.0 . When the bonuses were instead presented and translated into the other currency, participants judged both to be unfair to Brian, but still less so when the bonus was expressed in points $(M=-3.4 S D=21.9)$, as compared to the same bonus expressed in money $\left(M=-11.1, S D=24.5 ; t(401)=3.35, p<.001, d=0.33, \operatorname{diff}=7.8,95 \% \mathrm{CI}_{\text {diff: }} 3.2\right.$ to 12.3.$)$ 

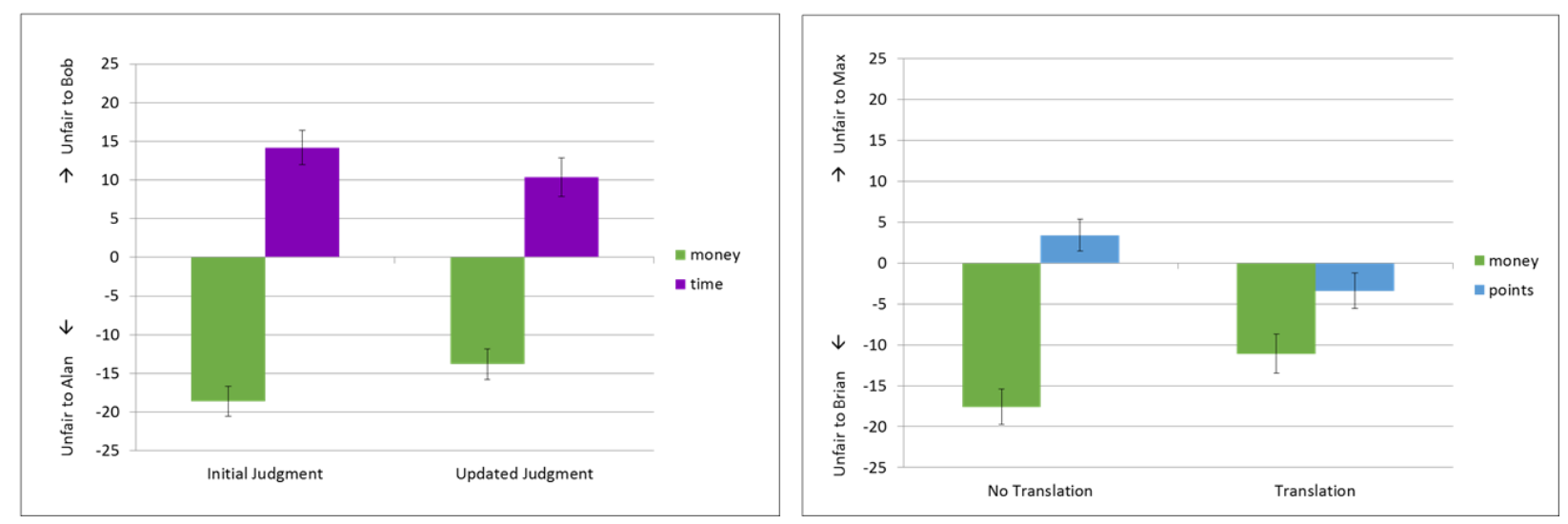

Fig. 2. Within-subjects fairness judgments before and after explicit translation into the other unit (Study 2a, left panel). Between-subjects fairness judgments with or without the translation between units (Study 2b, right panel). Error bars represent between-subjects standard errors.

\section{Study 3}

Studies 1 and 2 involve the evaluation of outcomes. We next tested whether arbitrary fairness would emerge when participants assigned outcomes rather than merely evaluated them.

\section{Study 3a}

\section{Participants and Design}

Participants in Study 3a were 400 workers recruited from MTurk (225 female, 175 male, $M_{\text {age }}=37.5, S D=12.2$ ). Study 3a used a 2 (units - between) by 2 (time - within) mixed design. Participants read about Alan and Bob who earn $\$ 50$ per hour and \$25 per hour respectively. All participants read that Alan and Bob were both caught running the exact same red light and were then asked to assign a fine to them, either in money or in community service hours. After indicating a fine to Alan and a separate fine to Bob, participants read on a new page that things expressed in money could be interpreted as the number of hours one needs to make that money, and vice versa. They were then told that they would be asked again to indicate what they thought would be a fair fine, but that they didn't have to change anything if they didn't want to. We 
expected that in the money condition, participants would increase Alan's fine more than Bob's (or reduce it less). We did not have strong expectations for the time condition. If participants asymmetrically adjusted the fines, they should reduce Alan's more than Bob's, but since people generally believe time is a fairer currency of exchange than money (Shaddy \& Shah, 2018), we expected this effect to be very small or even non-existent. Finally, we asked participants to write in 1-2 sentences how they came to the decision they made.

\section{Results}

Participants assigned different outcomes depending on the salient unit (see Figure 3). To analyze the results, we first translated fines assigned in the money condition to the equivalent work-hours needed to pay the fine (eighteen participants had one or more missing values). As predicted, participants initially gave a higher proportion of the fine to Alan when they assigned community service $(M=50.9 \%, S D=5.6 \%)$ as compared to the money condition $(M=34.9 \%$, $S D=5.2 \% ; t(383)=29.1, p<.001, d=2.97$, diff $=16.0 \%, 95 \% \mathrm{CI}_{\text {diff }}: 14.9 \%$ to $17.0 \%$. This difference became smaller at time 2 as indicated by a significant interaction effect in a repeatedmeasures ANOVA; $F(1,380)=16.9, p<.001, \eta_{\mathrm{p}}^{2}=.04$. As can be seen in Figure 3 (left panel), participants did not change their assigned fines in the time condition $(M=50.6 \%, S D=3.8 \%)$ but did increase Alan's fine in the money condition $(M=36.8 \%, S D=7.1 \% ; t(382)=-23.46, p$ $<.001, d=2.40$, diff $=13.8 \%, 95 \% \mathrm{CI}_{\text {diff: }} 12.6 \%$ to $14.9 \%$; see Figure 3 ).

\section{Study 3b}

\section{Participants and Design}

Participants in Study 3b were 229 workers recruited from MTurk (91 female, 137 male, 1 missing, $\left.M_{\text {age }}=33.5, S D=10.7\right)$. Study $3 b$ 's design was similar to that of Study 3a except that 
we used the same scenario as in Study 1b. Additionally, because of the high variance in Study 3a, we required participant's responses to add up to 40 points and $\$ 35$ in the points and dollars conditions respectively.

\section{Results}

The results of Study $3 \mathrm{~b}$ resemble those of Study 3a (see Figure 3 right panel).

Specifically, at time 1, Brian (the low income person) was assigned a much lower reward in the points condition $(43.8 \%, S D=17.4 \%)$ than in the money condition $(54.7 \%, S D=13.5 \%, t(227)$ $=5.3, p<.001, d=0.65$ diff $=10.9 \%, 95 \% \mathrm{CI}_{\text {diff: }} 6.9 \%$ to $\left.15.0 \%\right)$. This difference was attenuated at time 2, but Brian still received a lower reward in the points condition $(46.0 \%, S D=$ $17.3 \%)$ than in the money condition $(51.2 \%, S D=11.6 \%, t(227)=2.7, p<.01, d=0.36$, diff $=$ $5.2 \%, 95 \% \mathrm{CI}_{\text {diff: }} 1.4 \%$ to $9.0 \%$ ). This pattern was qualified by a significant interaction effect; $F(1,227)=14.1, p<.001, \mathrm{\eta}_{\mathrm{p}}^{2}=.06$. As in the previous studies, providing participants with a reinterpretation of their decision by translating the outcomes from one unit into another unit reduced inconsistencies but did not fully eliminate them, even when participants assigned the bonuses themselves.

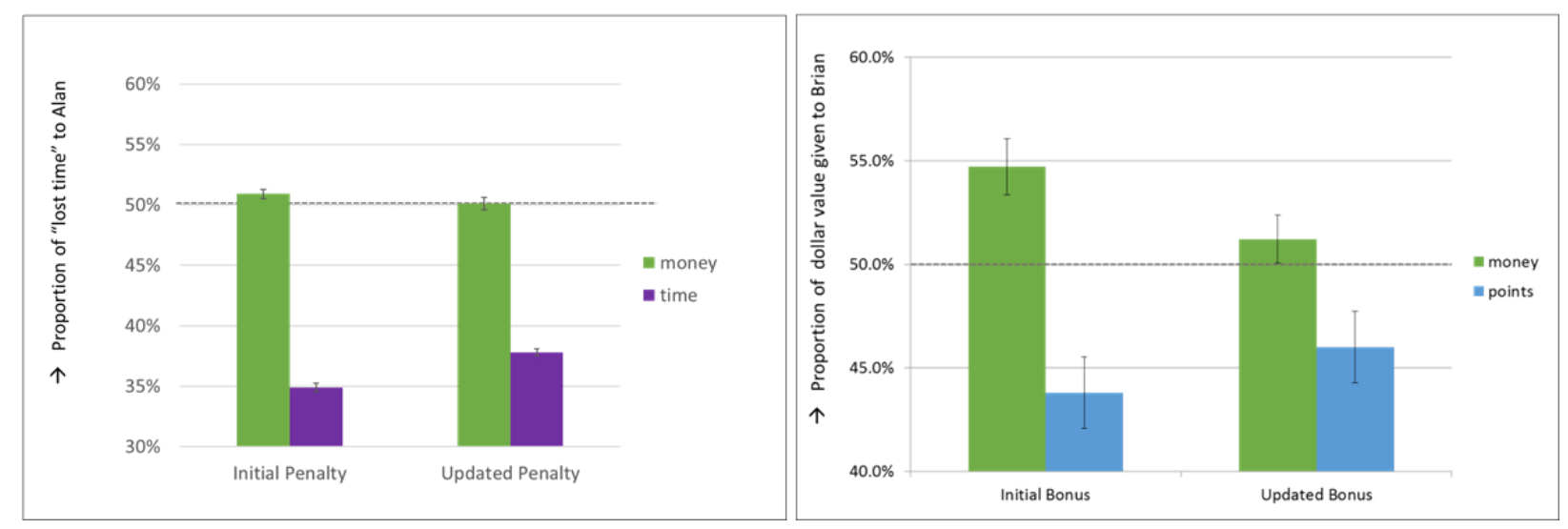


Fig. 3. Participants assign fines and bonuses differentially dependent on the unit that is more salient and update these assignments after the translation between currencies is made transparent. Error bars represent between-subjects standard errors.

\section{Study 4}

In Study 4 we tested whether a preference for arbitrary fairness would emerge in an incentive compatible setting, when participants had financial stakes in the outcome.

\section{Participants and Design}

Due to the cost of this study, we pre-registered a sequential analysis (Lakens, 2014). A total of 200 pairs of students were approached on campus to play a game of "cornhole" in which they made 16 attempts each to throw a small bag of corn through a hole in a wooden board. Only one person per pair actually participated in the real experiment (130 males, 69 females, 1 missing; $M_{\text {age }}=22.8, S D=6.6$ ). Study 4 used a 2 (units - between) by 2 (time - within) mixed design. Participants played collaboratively in teams of two and were told that they would earn money per point scored. They were also informed that if each of them scored at least three points, they could win an additional bonus. We then told them that there was a twist: one of them would earn $\$ 0.25$ per point scored, the other $\$ 0.50$ per point. We flipped a coin to randomly and transparently assign participants to roles. Nearly all groups earned the bonus. Then, the $\$ 0.25$ per-point player was told they could divide a bonus of \$5 (in the money condition) or 14 points (in the points condition) between themselves and the other team member. As in Study 3, after participants assigned the bonus, the research assistants translated the assigned outcomes to the other unit, and provided participants with the opportunity to change their allocations (although, of course, they did not have to do so).

\section{Results}


The results of this incentive-compatible study were very similar to the results of Study 3. Participants in the points condition initially gave themselves a smaller share of the bonus $(36.9 \%)$ as compared to participants in the money condition $(56.9 \% ; t(198)=6.25, p<.001, d=$ 0.88 , diff $=20.1 \%, 95 \% \mathrm{CI}_{\text {diff: }} 13.7 \%$ to $26.4 \%$ ). This difference between conditions became smaller at Time 2, interaction $F(1,197)=9.63, p=.002, \mathrm{\eta}_{\mathrm{p}}^{2}=.05$, but even at Time 2 participants still gave themselves a smaller share of the bonus in the points condition (42.2\%) as compared to the money condition $\left(55.8 \% ; t(197)^{1}=3.94, p<.001, d=0.56\right.$, diff $=13.6,95 \%$ $\mathrm{CI}_{\text {diff: }}$ 6.8\% to $20.4 \%$ ). In fact, even after seeing the explicit translation, participants in the points condition still gave themselves less than half of the bonus in dollar terms.

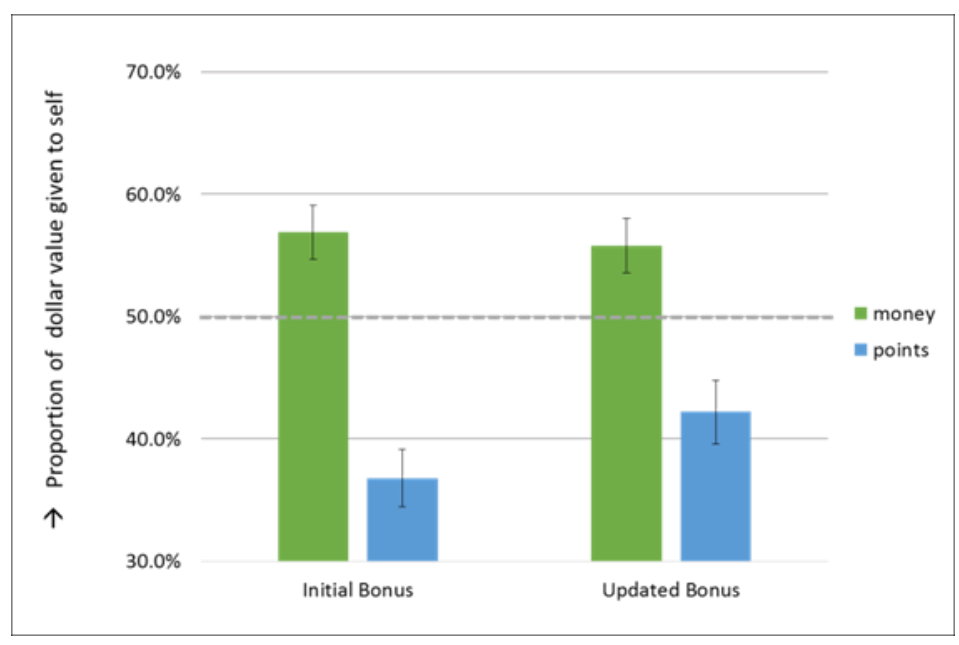

Fig. 4. Participants in the points condition award a smaller share of the bonus to themselves as compared to participants in the money condition. Making the exchange rate salient, reduces this difference. Error bars represent between-subjects standard errors.

Because participants in this study were recipients of the bonus (rather than third-party observers) they might try to maximize shared outcomes by assigning as many points as possible

\footnotetext{
${ }^{1}$ For one participant, the translation from points to money was miscalculated so this participant was dropped from the analysis.
} 
to the other (high-income) player. Some participants indeed did so, however, if the initial difference in outcomes between the two conditions was because participants were motivated to maximize shared outcomes, then this difference should have increased (rather than decreased) when participants were provided with more information.

\section{General Discussion}

In 9 experiments, people showed a preference for equating outcomes in whichever unit is salient, a preference we call arbitrary fairness. People showed this preference when evaluating the fairness of others' allocations (Studies 1a-2b) and when making their own allocations (Studies 3a-4). This persisted even when the units were arbitrary (e.g., points), when outcomes were translated between units for participants, and when self-interest would lead participants to allocate more resources to themselves. The preference for arbitrary fairness thus appears to be a general and robust phenomenon.

Inconsistent preferences often occur when people see a decision problem in isolation but disappear when the inconsistency is made salient (Hsee, 1996). For example, people think that increasing the cost of gasoline by $\$ 0.10$ to reduce deaths from air pollution is more justified when casualties will be reduced from 20,000 to 10,000 than from 200,000 to 190,000 when they see only one of the two scenarios (Kahneman \& Tversky, 2014). When participants see both, they find the price increase to be equally justified in both cases (Frisch, 1993). Sometimes, though, people resist changing their judgments even when they know what the "correct" response is. For example, people prefer lotteries that have more possible ways of winning (e.g., 9/100 vs. 1/10), even if the probability of winning is lower overall (Shah \& Oppenheimer, 2008). 
In this case, the intuition ("more winners is better") is strong enough to overcome peoples' explicit knowledge about probability (Waco \& Risen, 2017).

We believe the preference for arbitrary fairness is more like the latter class of problems. Explicitly translating between units reduced the size of the arbitrary fairness effect but never eliminated it (the average reduction in the effect size, $d$, after explicit translation was 0.44 across studies 2-4). Although we reliably find an attenuation in judgments when the equivalence between metrics is made salient, participants still judge the two situations differently in every study. This is likely because many participants do not change their judgments at all in response to the translation manipulation (between $36 \%$ and $74 \%$ across studies). It is not the case, however, that those who do update all update in the same way (e.g., those in the points conditions all update their judgments to equalize financial outcomes). Instead, we find that the participants who update do so in many different ways: some slightly adjust their initial judgment, whereas others fully equalize on the alternative unit. We believe that this reflects judgments being pulled in opposite directions by arbitrary fairness intuitions on the one hand, and explicit knowledge about equivalence across units of expression on the other (similar to Criterion "S", Sloman, 1996).

One practical implication of these results is that with some creative reframing, many fines and bonuses can be made to appear more or less fair. If for example, a policymaker wanted to implement a policy that naturally strikes people as unfair, she could change the salient units to make the policy appear fairer. A study reported in the SM investigates this possibility. Participants judged a proposal for the implementation of "day-fines" for extreme traffic violations. In version 1 , offenders would be sent to jail for 6 days. In version 2 , they would have to pay $20 \%$ of their monthly salary. In version 3, the initial proposal was jail for 6 days (as in 
version 1), but to reduce pressure on the prison system, they would instead have to pay the 6 days of missed wages (i.e., 20\% of their monthly income). While participants generally perceived the income-based fine to be less fair than prison time, when we framed the incomebased fine as the consequence of equal jail time, participants did not perceive this fine to be unfair but just as acceptable as jail time.

\section{Conclusion}

Fairness is central to some of the most important questions facing societies: What political systems are just? What economic transactions are acceptable? How much should the well-off be obliged to support the less fortunate? (Fehr \& Schmidt, 1999; Rawls, 2001;

Kahneman, Knetsch, \& Thaler, 1986b; Alesina \& Angeletos, 2018). Beliefs about fairness are central to group living, but as we show, they are also malleable. Understanding this malleability is therefore crucial to arriving at better answers to these questions. 


\section{References}

Alesina, A., \& Angeletos, G. M. (2005). Fairness and redistribution. American Economic Review, 95(4), 960-980.

Bolton, G. E., Katok, E., \& Zwick, R. (1998). Dictator game giving: Rules of fairness versus acts of kindness. International Journal of Game Theory, 27(2), 269-299.

Carlsmith, K. M., Darley, J. M., \& Robinson, P. H. (2002). Why do we punish? Deterrence and just deserts as motives for punishment. Journal of Personality and Social Psychology, 83(2), 284.

Chaiken, S. (1980). Heuristic versus systematic information processing and the use of source versus message cues in persuasion. Journal of Personality and Social Psychology, 39(5), 752.

De Langhe, B., \& Puntoni, S. (2016). Productivity metrics and consumers' misunderstanding of time savings. Journal of Marketing Research, 53(3), 396-406.

Denes-Raj, V., \& Epstein, S. (1994). Conflict between intuitive and rational processing: When people behave against their better judgment. Journal of Personality and Social Psychology, 66(5), 819.

Evers, E. R., Inbar, Y., Blanken, I., \& Oosterwijk, L. D. (2016). When do people prefer carrots to sticks? A robust "matching effect" in policy evaluation. Management Science, 63(12), 4261-4276.

Fehr, E., \& Schmidt, K. M. (1999). A theory of fairness, competition, and cooperation. The Quarterly Journal of Economics, 114(3), 817-868.

Fiske, A. P. (1991). Structures of social life: The four elementary forms of human relations: Communal sharing, authority ranking, equality matching, market pricing. Free Press. 
Frisch, D. (1993). Reasons for framing effects. Organizational Behavior and Human Decision Processes, 54(3), 399-429.

Furlong, E. E., \& Opfer, J. E. (2009). Cognitive constraints on how economic rewards affect cooperation. Psychological Science, 20(1), 11-16.

Graham, J., Haidt, J., \& Nosek, B. A. (2009). Liberals and conservatives rely on different sets of moral foundations. Journal of Personality and Social Psychology, 96(5), 1029.

Haidt, J. (2001). The emotional dog and its rational tail: a social intuitionist approach to moral judgment. Psychological Review, 108(4), 814.

Henrich, J., Boyd, R., Bowles, S., Camerer, C., Fehr, E., Gintis, H., ... \& Henrich, N. S. (2005). "Economic man" in cross-cultural perspective: Behavioral experiments in 15 small-scale societies. Behavioral and Brain Sciences, 28(6), 795-815.

Hsee, C. K. (1996). The evaluability hypothesis: An explanation for preference reversals between joint and separate evaluations of alternatives. Organizational Behavior and Human Decision Processes, 67(3), 247-257.

Hsee, C. K., Yu, F., Zhang, J., \& Zhang, Y. (2003). Medium maximization. Journal of Consumer Research, 30(1), 1-14.

Kahneman, D. \& Tversky, A. (1996). On the reality of cognitive illusions: A reply to Gigerenzer's critique. Psychological Review, 103: 582-591.

Kahneman, D., \& Frederick, S. (2002). Representativeness revisited: Attribute substitution in intuitive judgment. Heuristics and Biases: The Psychology of Intuitive Judgment, 49, 81.

Kahneman, D., \& Tversky, A. (2013). Choices, values, and frames. In Handbook of the 
Fundamentals of Financial Decision Making: Part I (pp. 269-278).

Kahneman, D., Knetsch, J. L., \& Thaler, R. (1986a). Fairness as a constraint on profit seeking: Entitlements in the market. The American Economic Review, 728-741.

Kahneman, D., Knetsch, J. L., \& Thaler, R. H. (1986b). Fairness and the assumptions of economics. Journal of Business, S285-S300.

Kohlberg L, \& Kramer R. (1969). Continuities and discontinuities in childhood and adult moral development. Human development, 12, 93-120.

Lakens, D. (2014). Performing high-powered studies efficiently with sequential analyses. European Journal of Social Psychology, 44(7), 701-710.

Larrick R.P. \& Soll J.B. (2008). The MPG Illusion. Science, 1593-1594.

Levin, I. P., Schneider, S. L., \& Gaeth, G. J. (1998). All frames are not created equal: A typology and critical analysis of framing effects. Organizational Behavior and Human Decision Processes, 76(2), 149-188.

Marlowe, F. W., Berbesque, J. C., Barr, A., Barrett, C., Bolyanatz, A., Cardenas, J. C., Esminder, J., Gurven, M., Gwako, E., Henrich, J., Henrich, N., Lesorogol, C., McElreath, R., \& Tracker, D. (2008). More "altruistic" punishment in larger societies. Proceedings of the Royal Society, 275, 587-590.

Messick, D. M. (1993). Equality as a decision heuristic. Psychological Perspectives on Justice: Theory and Applications, 11-31.

Piaget, J. (1923). The Language and Thought of the Child. Paris.

Rabin, M. (1993). Incorporating fairness into game theory and economics. The American Economic Review, 1281-1302.

Rai, T. S., \& Fiske, A. P. (2011). Moral psychology is relationship regulation: moral motives for unity, hierarchy, equality, and proportionality. Psychological Review, 118(1), 57. 
Rawls, J. (2001). Justice as fairness: A restatement. Harvard University Press.

Royzman, E. B., Kim, K., \& Leeman, R. F. (2015). The curious tale of Julie and Mark: unraveling the moral dumbfounding effect. Judgment \& Decision Making, 10(4).

Shaddy, F., \& Shah, A. K. (2018). Deciding who gets what, fairly. Journal of Consumer Research, 45(4), 833-848.

Shah, A. K., \& Oppenheimer, D. M. (2008). Heuristics made easy: An effort-reduction framework. Psychological Bulletin, 134(2), 207.

Simonsohn U. (2015) No-way interactions, 10.15200/winn.142559.90552 (2017).

Sloman, S. A. (1996). The empirical case for two systems of reasoning. Psychological Bulletin, 119(1), 3.

Turiel, E. (1983). The development of social knowledge: Morality and convention. Cambridge, United Kingdom: Cambridge University Press.

Walco, D. K., \& Risen, J. L. (2017). The empirical case for acquiescing to intuition. Psychological Science, 28(12), 1807-1820. 